\title{
Reducing infant morbidity with adolescent mothers
}

\begin{abstract}
Reducing infant morbidity with adolescent mothers is a significant public health problem in both rural and urban areas. Teenage pregnancy rates are extremely high in the United States but the majority of support, education and intervention programs deal with preventing pregnancy. This disregards the population of already pregnant teenagers and their developing babies, putting both at risk.

In applying the Health Promotion Model, developed by Dr. Pender from the expectancyvalue theory and social cognitive theory, adolescent mothers can be given the health and emotional support they need during pregnancy to increase positive outcomes for their infants.

Focus on the positive aspects, not the negative factors and risks, can have a significant impact on adolescent mothers. The Health Promotion Model encourages behavior and attitude to increase wellbeing and health as opposed to focusing on illness or what can go wrong. Adolescent mothers may already be in a situation where they are considered wrong, having made a mistake and other belittling or demeaning associations that lower their self esteem. Promoting a healthy and safe developmental environment for their babies while in the womb gives them a chance to take a fresh, positive and healthy start.
\end{abstract}

Volume 8 Issue 2 - 2017

\author{
Jill Diana Chasse \\ Capella University, USA
}

Correspondence: Jill Diana Chasse, Hygeia Public Health at Solstice Cafe \&Wellness Center, Capella University, USA. Email drjilldiana@gmail.com

Received: February 17, 2017 | Published: October 30, 2017

\section{Introduction}

Reducing infant morbidity with adolescent mothers is an issue that is rarely addressed as most attention is paid to reducing the adolescent pregnancy rate. The highest teenage birth rate in the developed world (41.1/1000) is in the United States. ${ }^{1}$ Although many risk reduction, prevention and deterrent efforts have been implemented, there are still teenage mothers. These mothers need special attention, care, education and support to achieve a healthy pregnancy and healthy newborn.

A young maternal age is correlated with both physical and psychological problems for mother and child. In a study conducted by Phipps, Blume, and DeMonner, even after adjusting for maternal race or ethnicity, prenatal care utilization, and marital status, infants born to early adolescent mothers had a three-fold higher risk (odds ratio $3.0,95 \%$ confidence interval $2.5,3.6$ ) of infant mortality compared with adult mothers. ${ }^{2}$ Infants from teenage mothers are also more likely to be born preterm, before their lungs or livers are completely developed, causing medical issues such as jaundice, asphyxia, and low birth weight. ${ }^{3}$

Higher birthrates are reported in adolescents from lower income and low SES families and communities than adolescents in higher income and SES populations. ${ }^{4}$ The Centers of Disease Control and Prevention has reported that research shows in addition to socioeconomic status, community characteristics and youth programs such as behavioral intervention and education campaigns have been effective in reducing pregnancy in adolescents, but have not adequately addressed prenatal care for those who have become pregnant. ${ }^{4}$

Birthrates for adolescents in the United States are highest in the Hispanic population. Not only within the US population are Latina teens having babies in a higher percentage than non Latina teens, but also within their own communities there is a high rate of pregnancy. Over half of Latinos girls become pregnant at least once before the age of $20 .^{5}$

Within their families and social contexts, pregnancy is not viewed as a negative consequence. Large families and fertility are signs of health, strength, and good fortune. ${ }^{6}$ Women are expected to have children young and raise a house full of kids. When teenagers become pregnant, they usually stay living with their parents, as extended families are also esteemed in the Latino community. Grandparents help to raise grandchildren, in-laws move in and help cook, and aunt and uncle spend a great deal of time with the family.

This cultural acceptance of large families allows teenagers to feel more comfortable about having sexual relations and procreating at a young age but does not address prenatal care, nutrition, and avoiding risky behaviors which put the mother and fetus at greater risk. ${ }^{5}$ Teenagers, especially Latina teens, like to articulate and express their individuality and independence, often at the risk of avoiding prenatal advice, care and guidance.

Even with this acceptance of early parenthood, the low acceptance of pregnancy care and risk reduction education can be detrimental to the developing fetus. The growing body of a teenage girl is not designed to carry and nurture a developing child. Therefore, both she and the child are at risk for nutritional deficits, muscle fatigue, internal injury, and depression. Furthermore, adolescents are typically in more perilous and precarious situations such as binge drinking, experimenting with illegal substances, unsafe driving, and unprotected sexual situations. These could all affect the developing child directly or indirectly through the mother's health status and emotional wellbeing. ${ }^{?}$

After the birth of their child many teenagers find that they become more dependent on their parents still living at home, or moving from one boyfriend to another when relationships fail. This can put the teenager and her already vulnerable child on a path of psychological and mental health problems, developmental disabilities, domestic violence and poverty. ${ }^{5}$

\section{Literature review}

\section{Possible reasons ${ }^{4}$}

There is a high probability of adverse outcomes in babies born to teenage mothers. The most typical outcomes are a preterm delivery 
with low birth weight or very low birth weight babies, and babies with low APGAR scores ${ }^{4}$ In this retrospective cohort study, researchers looked at multiple reasons that may be factors for adverse birth outcomes with teenage mothers. Included in these determinants were social environment, inadequate prenatal care, and biological immaturity.

The results of this large, population based study reflected the fact that although there seems to be a correlation in some research, low socioeconomic status, inadequate prenatal care and inadequate weight gain during pregnancy are not the main reasons for adverse birth outcomes in teenagers.

When a teenage mother conceives within 2 years of having her first period, the immaturity of her uterus or cervical blood supply can be a considerable reason for preterm birth. Additionally, a growing teenager's body needs vitamins and nutrients for which her developing baby may be in competition with. This study also showed that teenage mothers were more likely to be black, unmarried, to have smoked cigarettes during pregnancy, to have had inadequate prenatal care and have gained less weight during pregnancy. ${ }^{4}$

\section{Possible solutions. ${ }^{2}$}

The study utilized data from a computerized database of a University Hospital for the years 1994-2001, with a large population of 8514 primiparous women aged less than the age of $3 .^{2}$ Although prenatal and complications such as preeclampsia and adverse obstetric outcomes were lower with younger maternal age, there was a higher prevalence of prematurity and low birth weight in infants born to teenagers and greater risk of fetal death and anemia. It was also determined that maternal age $\leq 15$ years was a significant risk factor as this age group had the highest mortality rates, even when adjusted for other factors.

The research supported the assumption that babies born to adolescent mothers have a significantly higher morbidity and mortality rate than those babies born to adult mothers. This article attributes much of this high rate to social and environmental aspects. These aspects are controllable and therefore it is possible to reduce the risk of adverse birth outcomes. Suggestions such as developing support services targeted to adolescent mothers and their infants is one of the ways that this article proposes solutions to this public health problem. Additionally designing and implementing adolescent parenting programs for postnatal support that address the needs of their infants is a possible solution for reducing high morbidity.

\section{Strategies}

Alleviating the high morbidity rate of infants born from teenage mothers can be addressed through vigilant planning and effective design of an outreach and support preventive healthcare program. In order to design a more effective program to meet the needs of pregnant and parenting adolescents and their babies, the strategy used for the program will be based on the Health Promotion Model (HPM). Nola Pender, $\mathrm{PhD}, \mathrm{RN}$, published the Health Promotion Model (HPM) in 1982, explaining that this model was developed by using the expectancy-value theory and social cognitive theory, looking through a nursing lens. This model was most recently updated in 1996 (McEwen \& Wills, 2011).

Dr. Pender utilized this model for helping adolescents adopt physically active lifestyles, so it could very well be utilized for healthy teen pregnancy promotion, support and education.
"Teens and Tiny Ones" is an outreach program I would design utilizing the theoretical propositions of the health promotion model including the integration of prior behavior beliefs and characteristics. As defined in this model, behavior of teenage mothers would be motivated by the desire to increase well-being of both mother and chil. ${ }^{8}$ This approach to wellness would look at the current behavior and personal factors of the mother in relation to her life, pregnancy, baby and social situation. It would also look at behavior-specific cognitions and affect such as perceived benefits and barriers during pregnancy, interpersonal relationships and their changes during gestation, and ultimately behavioral outcomes, including commitments, demands, and the specification of health promoting behavior leading to a healthy pregnancy, birth and infancy.

The Teens and Tiny Ones outreach initiative based on the Health Promotion Model has high potential to be an effective and valuable method. Designing, developing and implementing the program to draw focus on the health of the mother and her tiny child, a child for whom she is ultimately responsible, is a way to draw a teen mother's attention to the fragile, delicate, vulnerable and susceptible being inside her. With that focus on protecting her child, the mother's enthusiasm, dedication and protective instincts can flourish, giving the child the best start as he or she beings life.

As part of the initial development process, a project design description, scope and assumptions would be defined. The design description would include an explanation of the goals and objectives for designing a program to reducing infant morbidity with adolescent mothers. The scope definition would identify what tasks would be included in this project and what would not be included. Background for evidence based methods would be defined and describe, including the quality and quantity of evidence available, literature reviews prior research and an explanation of the generation of new knowledge.

The target population needs to be directly involved with the entire lifecycle of the program, not just the implementation. I would present a course that works with a school or youth group, allowing the girls to set goals and design plans based on their desires and concerns. Listening to what they have to say about their home and family challenges, their expectations and their hopes and dreams.

The following tenets of the Health Promotion Model would be reflected in the development of materials (McEwen \& Wills, 2011).

i. Commitment to a plan of action is less likely to result in the desired behavior when other actions are more attractive and thus preferred over the target behavior.

ii. Perceived barriers can constrain commitment to action, a mediator of behavior as well as actual behavior.

iii. Perceived competence or self-efficacy to execute a given behavior increases the likelihood of commitment to action and actual performance of the behavior.

iv. Greater perceived self-efficacy results in fewer perceived barriers to a specific health behavior.

v. Positive affect toward a behavior results in greater perceived selfefficacy, which can in turn, result in increased positive affect.

vi. When positive emotions or affect are associated with a behavior, the probability of commitment and action is increased.

This model (Figure 2) illustrates a multi-faceted assessment process integrating an individual's interpersonal nature, behavior 
innate affect as well as the effect of interacting with external factors such as family and peers, leading to an agreed upon plan of action for health promoting behavior.

\begin{tabular}{|c|c|c|}
\hline $\begin{array}{l}\text { Individual Characteristics } \\
\text { and Experiences }\end{array}$ & $\begin{array}{l}\text { Behavior-Specific Cognitions } \\
\text { and Affect }\end{array}$ & Behavioral Outcomes \\
\hline $\begin{array}{l}\text { - Prior related } \\
\text { behavior } \\
\text { - Personal factors: } \\
\text { biological, } \\
\text { psychological, } \\
\text { sociocultural }\end{array}$ & $\begin{array}{l}\text { - Perceived benefits of } \\
\text { actions } \\
\text { - Pereeived barriers to } \\
\text { actions } \\
\text { - Perceived self-efficacy } \\
\text { - Activity-related affect } \\
\text { - Interpersonal influences: } \\
\text { (family, peers, providers); } \\
\text { norms, support, models } \\
\text { - Situational influences: } \\
\text { options, demand } \\
\text { characteristics, aesthetics }\end{array}$ & $\begin{array}{l}\text { Immediate competing } \\
\text { demands (low } \\
\text { control) and } \\
\text { preferences ( high } \\
\text { control) } \\
\text { - Commitment to a } \\
\text { plan of action } \\
\text { - Health promoting } \\
\text { behavior }\end{array}$ \\
\hline
\end{tabular}

Figure I Theoretical Propositions of the Health Promotion Model (McEwen \&Wills, 20I I).

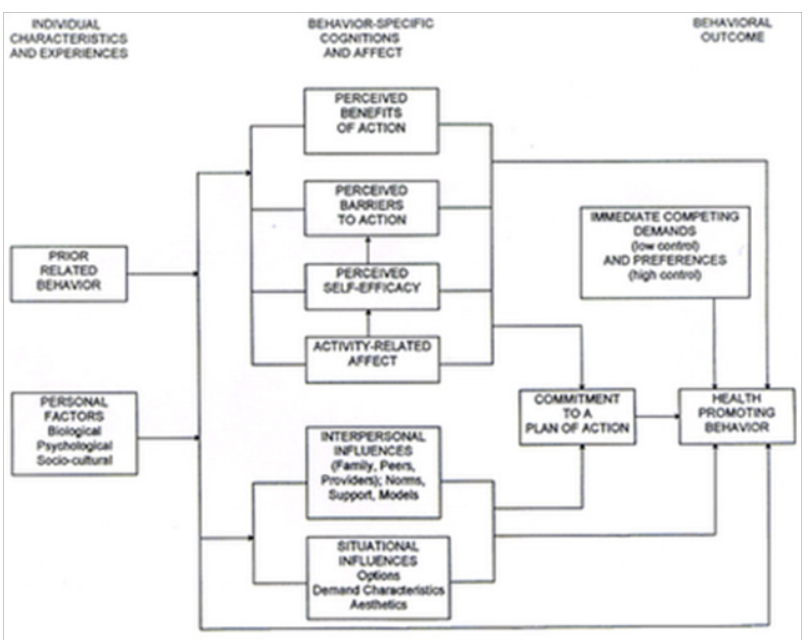

Figure 2 Revised Health Promotion Model. (Kozier, 2004).

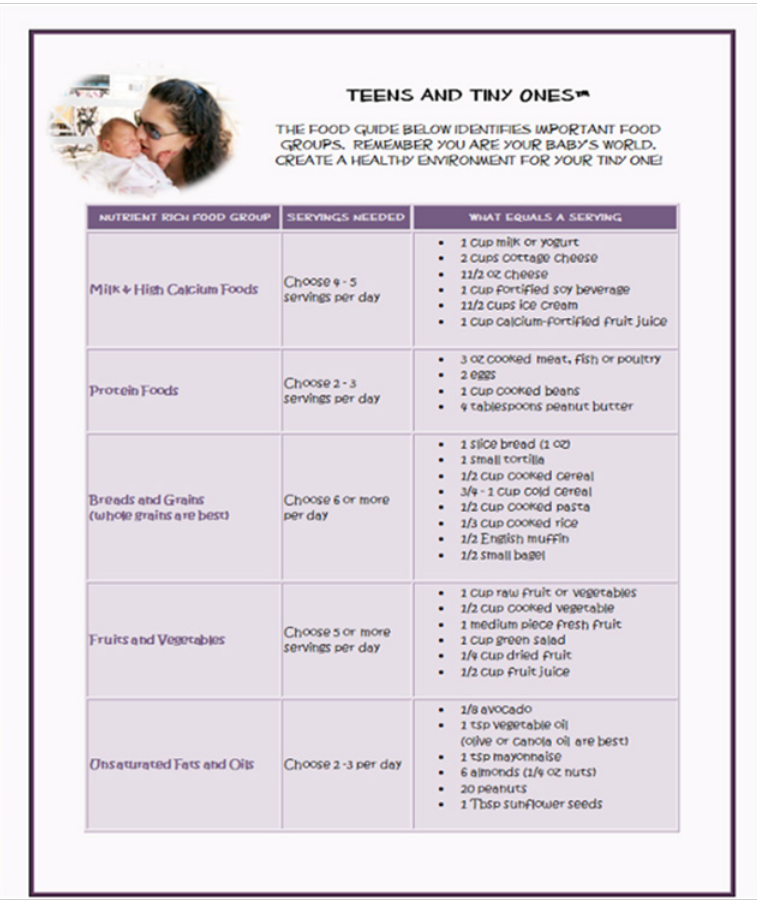

Figure 3 Nutritional guidelines for pregnant adolescents.

\section{Implementation plan}

Implementing the Teens and Tiny Ones (TTO) outreach program would begin by the development of a Program Pack, similar to the Department of Health and Human Services' "Business Case for Breastfeeding," a comprehensive package of educational materials, training videos, handouts, tools and area specific resources provided to local health departments. A rural and urban version of the Program Pack will be designed. In each of these areas, there will a minority specific subset for Hispanic/Latina teens and African American teens as these two populations continue to have a high rate of teen pregnancy. ${ }^{9}$

The Teens and Tiny Ones (TTO) Program Pack will include:

a. A TTO promotional flyer.

b. A TTO introduction DVD with video clips of teen parents showing prenatal visits, birth classes and proper prenatal care.

c. A list of nutritional guidelines for pregnant adolescents.

d. Guidebook "My school decisions".

e. Life Skills class outline.

f. Guidelines for healthy relationships.

g. A list of pregnancy Dos and Don'ts geared to teens.

h. Suggestions for healthcare providers/ parents/ schools to engage teens in open dialogues.

i. "Empowering Myself and My Baby" a teen booklet for active childbirth preparation.

j. How to find prenatal care without insurance- guidelines for free resources and low cost support.

k. All About Doulas- information sheet and local resources

1. Keeping Us Safe- guidelines to recognize, avoid or manage domestic violence.

m. Life in the Womb- a month by month picture guide to the baby's development and abilities.

These documents, templates and tools could be easily personalized to fit the specific needs of the local health department. Specific area resources will also be defined for the TTO Program Pack as addressed above. This will include:

Rural TTO: This program would play upon the dense social networks that are prevalent in rural areas, with focus on psychosocial health, ways to deal with being a pregnant teenager in a small close-knit but chatty community. It would address access to care issues including health literacy, transportation, finding a specialist out of town, virtual and telemedicine options for support and counseling, and would also touch upon the positive aspects of rural life, such as long held family ties and friendships.

Urban TTO: The Urban TTO sub program would speak to wide disparities in socioeconomic status and population density that may lead to higher risk behaviors including easy access to illegal substances and the effect on pregnant teenagers and their babies. This program would also address poor air quality and crime rates as well as accessing city resources and implementing school-based programs, as urban areas are more likely to accept reproductive related programs in their education system. 
Specific to Hispanic/Latina teens: Worksheets would have a lot of open ended questions, questions about extended family, family values, and cultural sensitivity. The templates would be more open and flexible to allow local health departments to develop a teaching curriculum that has a personal approach, "personalismo," as Latina teens accept individualized, personalized and specific education as opposed to the one size fits all model with an canned curriculum and wide audience. Research shows that Latina teenagers respond better to this approach. ${ }^{5}$ It is also important to address the fact that many Latina youth are conceiving and birthing babies before even entering high school, so developing materials for middle school age girls would be imperative. ${ }^{5}$

Reference materials would include culturally appropriate books and publications such as: Parenting with Pride Latino Style: How to Help Your Child Cherish Your Cultural Values and Succeed in Today's World, by Carmen Inoa Vazquez, Raising Nuestros Ninos: Bringing Up Latino Children in a Bicultural World, by Gloria G. Rodriguez and I Am Latino: The Beauty in Me, by Myles C. Pinkney and Sandra L. Pinkney.

Specific to African American teenagers: The materials would address some of the historic, social and economic problems their families may have faced and ways to overcome these situations or stigmas to maintain a positive cultural identity. African proverbs and stories would be used in the materials, to respect the cultural tradition of storytelling and integrate this practice into parenting education. ${ }^{9}$ Research reflects many single-family households in the AfricanAmerican population, so materials would include single mothering support and educational information regarding this topic.

Reference materials would include culturally appropriate books and publications such as: Developing Positive Self-Images and Discipline in Black Children, by Dr. Jawanza Kunjufu, Raising Black Children, by James P. Comer and Alvin F. Poussaint and The Black Parenting Book: Caring for Our Children in the First Five Years, by Allison Abner, Linda Villarosa and Anne C. Beal.

Staffing of TTO at the Program Level would include a program manager, a budget analyst, a policy specialist, a public health practitioner with focus in maternal/child health programs, and subject matter experts (SMEs) in mental health, such as a social worker or psychologist, and an expert in maternal/perinatal health, most likely an obstetrician or a midwife. Making sure that this program was staffed with people who were culturally sensitivity non-judgmental is also vital to success. ${ }^{5}$

For the implementation staff at the local health department level, I would suggest in the program training materials that local health departments chose their staff carefully, based on their honesty, responsiveness, and recognition of cultural and personal values. I would be sure that educator training for this program included ways to talk to parents, relationship highs and lows, and understanding the importance of prenatal and pediatric healthcare, balancing that with the ways teen pregnancy and parenting could be the most effective, healthy and successful. ${ }^{10-18}$

\section{Evaluation}

Program evaluation will be conducted at 6 months after the initial implementation of the program in the first local health department. By the 6 month mark, pilot implementation of 10 local health departments would have completed first implementation. A risk/benefit analysis will be conducted with data received through questionnaires as well as records on infant morbidity and adverse birth effects in the study population from the initial implementation. There will also be a written evaluation completed after analysis and review by the TTO Workgroup involving research and program staff from the Office of Adolescent Health $(\mathrm{OAH})$ and the Maternal and Child Health Bureau (MCHB) of the Health Resources and Services Administration (HRSA), both under the Department of Health and Human Services, as well as select Local Health Department officials, and TTO program subject matter experts $[19,20]$.

The TTO Workgroup will evaluate the program with random assignment and quasi experimental evaluation processes. The first experimental evaluation study will examine the implementation and impacts of the Teens and Tiny Ones program. Random sites will be selected and researchers will determine if the program can achieve impacts with different populations and setting..$^{21-23}$

\section{Revisions}

Program revision will be a living process. There will be an official review at 12 and 18 months after official kick off and program implementation. Reviews will include the TTO Workgroup to determine if the program continues to achieve positive impacts that were found in the original evaluations or if revisions are necessary. ${ }^{24}$

At 24 months after the initial kick-off, TTO will enter the annual review stage. Annual reviews will be less intense than the first two reviews and revisions will only be added if necessary. An official amendment to the project statement of work will be recommended for major revisions and will be reviewed by the TTO Workgroup as appropriate. ${ }^{25,26}$

\section{Conclusion}

It is possible for a teenage mother to have a healthy pregnancy, birth and infant, but she must be able to navigate and mitigate the associated risks with adolescent childbearing. Alleviating physical and psychological adverse effects during pregnancy and birth which could significantly impact the morbidity of the infant must be supported by education and outreach initiatives to influence a teenage mother to seek prenatal care and support. Focus on promotion of adolescent wellness and promoting healthy pregnancies in order to prevent complications such as low birth weight can be used in both urban and rural environments, but the program must be designed specifically for the target population in each are. ${ }^{27-33}$

The Teens and Tiny Ones Outreach Initiative further emphasizes the importance of incorporating appropriate multidisciplinary interventions into the prenatal care of adolescent mothers in order to minimize their economic deprivation and adverse birth outcomes. ${ }^{7}$ Health Promotion Model defines health as "a positive dynamic state not merely the absence of disease." This increases a teenage mother's level of well being in a multidimensional manner, taking into consideration interactions with her environment, individual characteristics, behavior-specific cognitions and behavioral outcomes (Nursing Theories, 2012).

\section{Acknowledgments}

None.

\section{Conflicts of interest}

$$
\text { None }
$$

\section{References}

1. Ventura S, Abma J, Mosher W, Henshaw S Estimated pregnancy rates by outcome for the United States, 1990-2004. Natl Vital Stat Rep. 2008; 56(15):1-25. 
2. Phipps M, Blume J, DeMonner S Young maternal age associated with increased risk of neonatal death.Obstet Gyneco. 2002;1 100(3): 481-486.

3. Roth J, Hendrickson J, Schilling M, Stowell DW The risk of teen mothers having low birth weight babies: implications of recent medical research for school health personnel. Journal of School Health. 1998; 68(7): 271-275.

4. Chen XK, Wen SW, Fleming N, Demissie K, Rhoads GG, et al. Teenage pregnancy and adverse birth outcomes: a large population based retrospective cohort study. Int J Epidemio. 2007;1 36(2): 368-373.

5. Vexler E, Suellentrop K Bridging Two Worlds: How Teen Pregnancy Prevention Programs Can Better Serve Latino Youth. National Campaign to Prevent Teen Pregnancy, Washington, DC, USA, pp. 2006; 1-40.

6. Mac Donald H Hispanic Family Values? City Journal. The Manhattan Institute, New York, USA. 2006

7. de Vienne CM, Creveuil C, Dreyfus M Does young maternal age increase the risk of adverse obstetric, fetal and neonatal outcomes: a cohort study. Eur J Obstet Gynecol Reprod Bio. 2009;1 147(2):151-156.

8. Kozier B, Erb G, Berman A, Snyder S Fundamentals of Nursing Concepts, Process, and Practice. (7th edn), Pearson Education South Asia Pte Ltd. Philippines, USA. 200

9. Morgan S, Antonio McDaniel, Andrew T Miller, Samuel H Preston Racial differences in household and family structure at the turn of the century. American Journal of Sociology. 1993; 98(4): 799-828.

10. Ajzen I The theory of planned behavior. Organizational Behavior and Human Decision Processes. 1991; 50(2):179-221.

11. Allen M, Svetsz MV, Hardeman R, Resnick MD What research tells us about Latino parenting practices and their relationship to youth sexual behavior. The National Campaign to Prevent Teen and Unplanned Pregnancy. 2008; p. 1-24.

12. Alves JG, Cisneiros RM, Dutra LP, Pinto RA Perinatal characteristics among early (10-14 years old) and late (15-19 years old) pregnant adolescents. BMC Res Note. 2012;s 5: 531

13. Antonio AL, Chang MJ, Hakuta K, Kenny DA, Levin S, et al. Effects of racial diversity on complex thinking in college students. Psychol Sc. 2004;i 15(8): 507-510.

14. Ayanian JZ, Weissman JS, Schneider EC, Ginsburg JA, Zaslavsky AM Unmet health needs of uninsured adults in the United States. JAMA. 2000; 284(16): 2061-2070.

15. Black JM, Hawks JH, Keene AM Medical surgical nursing. (6th edn), Elsevier Mosby, Philadelphia, USA. 2006

16. Blank R, M Dabady, C Citro, et al. Measuring Racial Discrimination. National Academies Press, Washington, DC, USA. 2004

17. Bowman MA, Prelow HM, Weaver SR Parenting behaviors, association with deviant peers, and delinquency in African American adolescents: A mediated-moderation model. Journal of Youth and Adolescence. 2007; 36(4): 517-527.

18. Catalano J The Mexican Americans. Chelsea House, New York, USA 1988

19. Comas-Díaz L Hispanics, Latinos, or Americanos: The evolution of identity. Cultural Diversity and Ethnic Minority Psychology. 2001; 7(2): 115-120.

20. Coyle K, Basen-Engquist K, Kirby D, Parcel G, Banspach S, et al. Safer choices: reducing teen pregnancy, HIV, and STDs. Public Health Report. 2001;116 Suppl 1: 82-93.

21. Gilliam ML, Warden MM, Tapia B Young Latinas recall contraceptive use before and after pregnancy: a focus group study. J Pediatr Adolesc Gyneco. 2004;1 17(4): 279-287.

22. Khashan AS, Baker PN, Kenny LC. Preterm birth and reduced birthweight in first and second teenage pregnancies: a register-based cohort study. BMC Pregnancy and Childbirth. 2010;10:36.

23. Kitson C. Young maternal age was associated with increased risk of postneonatal death in full term, healthy infants. Evid Based Nurs. 2003;6(2):57

24. Lenardson JD, Ziller EC, Coburn AF, et al. Profile of rural health insurance coverage: A chartbook. Maine Rural Health Research Center, Portland, ME, USA. 2009

25. Marriner TA, Raile AM. Nursing theorists and their work. In: Sakraida T. Nola J. Pender (Eds.), The Health Promotion Model. (5th edn), Mosby, St Louis, USA. 2005.

26. Mcanarney E. Adolescent Pregnancy in an Urban Environment: Issues, Programs, and Evaluation. Am J Dis Child. 1992;146(11):1390.

27. Nunez AE. Transforming cultural competence into cross-cultural efficacy in women's health education. Acad Med. 2000;75(11):10711080

28. Polit DF, Beck CT. Nursing research: Principles and methods. (7th edn), Lippincott Williams \& Wilkins, Philadelphia, USA. 2007.

29. Potter PA, Perry AG. Fundamentals of nursing. (6th edn) Elsevier Mosby, St. Louis, USA. 2006.

30. Sheets RH. Diversity pedagogy: Examining the role of culture in the teaching-learning process. Allyn \& Bacon, Boston, USA. 2005.

31. The National Campaign to Prevent Teen and Unplanned Pregnancy. Latino Initiative. 2013.

32. University of Massachusetts. UMASS Medical Interpreter Services. Massachusetts General Hospital. Boston, MA, USA. 2002.

33. Nora J Pender. University of Michigan School of Nursing, USA. 2006 